JOURNAL

OF TOURISM

AND ECONOMIC
Journal of Tourism and Economic Vol.3, No.2, 2020, Page 104-112

ISSN: 2622-4631 (print), ISSN: 2622-495X (online)

Email: jurnalapi@gmail.com

Website: http://jurnal.stieparapi.ac.id/index.php/JTEC

DOI: https://doi.org/10.36594/jtec.v3i2.95

\title{
ANALISIS FAKTOR PENDUKUNG DAN PENGHAMBAT PENGELOLAAN ATRAKSI WISATA AIR MANCUR SRI BADUGA
}

\author{
Muhamad Nur Alfi Syahrin \\ Universitas Komputer Indonesia \\ nuralfisyahrin@mahasiswa.unikom.ac.id \\ Poni Sukaesih Kurniati \\ Universitas Komputer Indonesia \\ poni.sukaesih@email.unikom.ac.id
}

\begin{abstract}
The purpose of this study is to identify the supporting and inhibiting factors of the management of the Sri Baduga Fountain Park, Purwakarta Regency. The method used in this research is descriptive with a qualitative approach, data models used is by literature studies, to test the validity of the data is done through triangulation, while for data analysis is done through an interactive model. The results showed that the supporting factors in the management of the Sri Baduga Fountain Park tourism object consisted of: entertainment concept factors; The factor of application of Sundanese culture; and marketing factors, as for the inhibiting factors of the Sribaduga Fountain Park tourist attraction, including the condition of the supporting facilities; Water resource factor; and management funding factors. Researchers recommend that DISPORAPARBUD Purwakarta Regency be able to evaluate the concept of funding tourist attraction facilities; looking for water management concepts; and socializing the importance of implementing ticket-based payments and/or charges at Sri Baduga Fountain Park.
\end{abstract}

Keywords : Tourism Attraction, Fountain, Purwakarta Regency 


\begin{abstract}
ABSTRAK
Tujuan penelitian ini adalah untuk mengidentifikasi faktor pendukung dan faktor penghambat dari pengelolaan objek wisata Taman Air Mancur Sri Baduga Kabupaten Purwakarta. Metode yang digunakan dalam penelitian ini adalah deskriptif dengan pendekatan kualitatif, pengumpulan data yang digunakan adalah melalui studi literatur, untuk uji keabsahan data dilakukan melalui triangulasi, sedangkan untuk analisis data dilakukan melalui model interaktif. Hasil penelitian menunjukan bahwa faktor pendukung dalam pengelolaan objek wisata Taman Air Mancur Sri Baduga terdiri atas: Faktor konsep hiburan; Faktor penerapan kebudayaan Sunda; dan Faktor pemasaran, adapun faktor penghambat dari objek wisata Taman Air Mancur Sribaduga diantaranya: Faktor kondisi fasilitas pendukung; Faktor sumber daya air; dan Faktor pendanaan pengelolaan. Peneliti menyarankan agar DISPORAPARBUD Kabupaten Purwakarta agar dapat mengevaluasi konsep pendanaan fasilitas objek wisata; mencari konsep manajemen pengairan; dan mensosialisasikan pentingnya penerapan pembayaran berbasis tiket dan atau retribusi di Taman Air Mancur Sri Baduga.
\end{abstract}

Kata kunci : Atraksi Wisata, Air Mancur, Kabupaten Purwakarta 


\section{PENDAHULUAN}

Wulandari, \& Wahyuni (2018) menjelaskan bahwa Purwakarta memiliki 47 objek wisata yang terdiri dari wisata alam, religi, sejarah dan buatan. Air mancur Sri Baduga merupakan salah satu destinasi wisata di Kabupaten Purwakarta. Selain itu Wulandari, \& Wahyuni (2018) menjelaskan bahwa jumlah wisatawan yang berkunjung ke Taman Air Mancur Sri Baduga pada tahun 2016 berdasarkan Data objek dan daya tarik wisata Dinas Pemuda, Olahraga, Pariwisata, dan Kebudayaan Kabupaten Purwakarta (DISPORAPARBUD) 2016 Taman Air Mancur Sri Baduga menjadi destinasi wisata yang paling banyak dikunjungi wisatawan.

Tercatat jumlah berdasarkan penelitian dari Wulandari, \& Wahyuni (2018) wisatawan yang berkunjung sebesar 240.080 yang terdiri dari 80 wisatawan mancanegara dan 240.000 wisatawan lokal. Taman wisata Air Mancur Sri Baduga merupakan top-five destinasi terbaik di Indonesia, destinasi wisata ini menyuguhkan pertunjukan air mancur dengan pagelaran seni budaya.

Dilansir dari situs Purwakartakab.go.id (2019) secara historis perkembangan Situ Buleud sebagai destinasi pariwisata di Kabupaten Purwakarta memiliki perjalanan yang Panjang, destinasi wisata ini dulunya merupakan sebuah danau yang dijadikan tempat pemandian hewan Badak. Selain itu berdasarkan Purwakartakab.go.id (2019) asalusul mengenai Situ Buleud berkaitan dengan perpindahan ibukota Karawang dari Wanayasa ke Sindangkasih tepatnya sejalan dengan pembangunan infrastruktur awal kota Purwakarta. Situ Buleud dibangun atas inisiatif Bupati R.A Suriawinata dan memiliki jangka waktu pembangunan satu tahun terhitung dari 1830-1831.

Sjoraida, \& Anwar (2019) menjelaskan bahwa proses pembangunan pertunjukan air mancur Sri Baduga Maharaja dimulai pada tahun 2013 yang dilakukan menjadi tiga tahap. Tahap pertama dilakukan pada tahun 2014, tahap kedua dilakukan pada tahun 2015, dan tahap ketiga pada tahun 2016. Destinasi wisata air Mancur Sri Baduga diresmikan pada 6 Januari 2017 oleh Menteri Pariwisata Arief Yahya bersama bupati Purwakarta H. Dedi Mulyadi.

Penelitian mengenai pariwisata dan pengelolaan sumber daya air sudah banyak dilakukan oleh penelitian terdahulu dengan sudut pandang yang berbeda. Diantaranya adalah penelitian yang dilakukan dengan mengukur tingkat efektivitas program pariwisata yang dilakukan oleh Winasis dan Setiawan (2016) hasil penelitian tersebut menunjukan efektivitas program wisata telah berhasil dilakukan, hal ini disebabkan efektifitas dapat terjadi karena telah dilakukan pembentukan Kelompok Sadar Desa yang merupakan gabungan dari Gabungan Kelompok Tani yang menjalin kerjasama dengan Jatim Park Foundation dan lembaga swadaya masyarakat.

Sudut pandang lain mengenai pariwisata dengan fokus kepada faktor pendorong dan penghambat objek wisata alam Bola Palelo dilakukan oleh Mellu dkk (2018). Lokasi Penelitian dilakukan di Kecamatan Mollo Tengah, Kabupaten Timor Tengah Selatan. Adapun hasil penelitian tersebut menjelaskan bahwa lokasi wisata secara geografis merupakan lembah yang didukung dengan kondisi pemandangan alam dengan kondisi yang sejuk, perencanaan pariwisata oleh Dinas Pariwisata Timor Tengah Selatan sudah direncanakan dengan menata dan membuat pondok/tempat-tempat berteduh bagi wisatawan yang kemudian diintegrasikan dengan wisata minat khusus seperti panjat tebing dan paralayang. Sedangkan faktor penghambat yang terdapat dari objek wisata ini yaitu:

- Aspek Sarana;

- Aspek Prasarana;

- Aspek Tata Laksana/Infrastruktur;

- Aspek Masyarakat yang meliputi lingkungan dan budaya;

- Aspek Kelembagaan;

- Aspek Pengelolaan;

- Aspek Pengusaha dan;

- Aspek Penelitian dan Pengembangan 
Sudut pandang penelitian pengelolaan pariwisata dengan konteks strategi pengelolaan wisata pernah dilakukan oleh Avinda dkk (2016). Hasil dari penelitiannya menunjukan bahwa Dinas Kebudayaan dan Pariwisata Kabupaten Banyuwangi agar mengkaji ulang program bauran promosi yang kurang efektif, mengadakan pelatihan kepramuwisata dan Bahasa Inggris, memperbanyak Tourist Information Center dan menjalin kerjasama dengan pemangku kebijakan lainnya.

Sedangkan penelitian mengenai pembiayaan pengelolaan sumber daya air yang berkelanjutan pernah dilakukan oleh Hilbig dan Rudolph (2019). Hasil penelitian menunjukan bahwa mekanisme pengelolaan sumber daya air adalah dengan cara Lean Cost dimana sangat berpengaruh terhadap air dan fasilitasi air limbah. Perbedaan penelitian ini dengan penelitian sebelumnya adalah untuk mengidentifikasi faktor pendukung dan penghambat dalam pengelolaan objek wisata Taman Air Mancur Sri Baduga di Kabupaten Purwakarta.

\section{TINJAUAN LITERATUR}

\section{Konsep Perencanaan Pembangunan Pariwisata}

Menurut Illah (2019) Pariwisata merupakan kunci pembangunan, kesejahteraan, dan kebahagiaan, pariwisata merupakan sektor unggulan karena dari investasi pariwisata dapat menciptakan pendapatan negara, penciptaan lapangan kerja, pengembangan usaha, dan pengembangan infrastruktur. Dengan demikian pariwisata merupakan sebuah aspek pendukung dari keberlangsungan pembangunan yang terdapat dalam sebuah daerah. Pariwisata juga dapat menjadi penggerak bagi sektor pembangunan lain pada sebuah kawasan wisata.

Menurut Riyadi dan Bratakusumah dalam Kawengian dkk (2018) menjelaskan bahwa keberhasilan pembangunan pariwisata harus memperhatikan lima faktor, yang antara lain: 1) Faktor Lingkungan; 2) Sumber daya
Manusia; 3) Sistem yang digunakan; 4) Perkembangan ilmu dan teknologi; 5) dan Faktor Pendanaan. Dengan demikian suksesnya sebuah pembangunan pariwisata terdiri dari beberapa faktor yang saling bersinergi satu dengan yang lainnya.

Sebagai contoh berdasarkan hasil penelitian Susanto dan Kiswantoro (2020) sebuah limbah pada lingkungan Sungai Mahakam merupakan faktor penghambat eksternal dari pengelolaan wisata susur sungai Mahakam. Selain itu pembangunan wisata juga memerlukan sebuah kerjasama antara masyarakat dan pengelola wisata, sebagaimana penelitian dari Hermawati dan Winarno (2020) yang menjelaskan bahwasanya terdapat kerjasama yang baik antara warga selaku pengelola Desa wisata Ngalrenggeran dengan berbagai pihak pemerintahan.

Faktor lingkungan menurut Riyadi dan Bratakusumah dalam Kawengian dkk (2018) terdiri dari tiga aspek yang perlu diperhatikan seperti aspek masyarakat, lingkungan, dan budaya. Masyarakat, lingkungan dan budaya pada faktor lingkungan merupakan sebuah aspek yang saling berhubungan karena terkait bagaimana sebuah pariwisata berjalan sesuai permintaan wisatawan yang tentu harus mempertimbangkan lingkungan sekitar dan budaya lokal.

Aspek masyarakat menurut Riyadi dan Bratakusumah dalam Kawengian dkk (2018) menjelaskan bahwa perencanaan pembangunan pariwisata harus mempertimbangkan kebetuhan akan layanan yang diperlukan bagi wisatawan, selain itu masyarakat juga perlu untuk dibina agar tumbuh jiwa masyarakat yang sadar wisata yang nantinya akan membuat wisatawan nyaman dan memberikan umpan balik kepada masyarakat. Aspek kedua adalah aspek lingkungan, menurut Riyadi dan Bratakusumah dalam Kawengian dkk (2018) lingkungan dalam objek wisata harus dapat dipelihara agar tidak rusak dan tercemar. Aspek terakhir dalam faktor lingkungan adalah aspek budaya, dimana menurut Riyadi dan Bratakusumah dalam Kawengian dkk 
(2018) merupakan sebuah aspek dimana suatu budaya dalam sebuah objek wisata tidak perlu diganti dengan budaya baru, namun cukup menjaga kelestarian dan dijadikan sebagai aspek unggulan.

Faktor sumber daya manusia menurut Riyadi dan Bratakusumah dalam Kawengian dkk (2018) mencakup bagaimana suatu sumber daya manusia dapat mengelola dan memelihara destinasi wisata tersebut. Peran sumber daya manusia ini mencakup wisatawan dan pengelola objek wisata.

Faktor sistem yang digunakan menurut Riyadi dan Bratakusumah dalam Kawengian dkk (2018) merupakan faktor yang terdiri dari dua hal utama dalam merencanakan sebuah konsep perencanaan pariwisata yakni permintaan (Demand) dan penawaran (Supply). Konsep perencanaan pariwisata harus dapat menyesuaikan bagaimana konsep penawaran dari destinasi wisata dengan permintaan wisatawan.

Faktor perkembangan ilmu dan teknologi menurut Riyadi dan Bratakusumah dalam Kawengian dkk (2018) menjelaskan bahwa destinasi wisata harus dapat menyesuaikan pelayanan dengan perkembangan teknologi dan keilmuan. Sedangkan faktor pendanaan menurut Riyadi dan Bratakusumah dalam Kawengian dkk (2018) merupakan sebuah faktor dimana pemerintah harus dapat memprioritaskan kebutuhan pendanaan untuk pembangunan pada aspek lain di wilayahnya.

\section{METODE, DATA, DAN ANALISIS}

Metode penelitian yang digunakan dalam penelitian ini adalah penelitian kualitatif dengan pendekatan deskriptif. Nasution dalam Sugiyono (2017:224) kemudian menjelaskan bahwa instrument dalam penelitian kualitatif adalah peneliti sendiri. Pengumpulan data dilakukan melalui studi pustaka yakni melihat referensi dari beberapa artikel penelitian sebelumnya dengan topik ranah pariwisata dengan fokus kepada permasalahan di Taman Sri Baduga Kabupaten Purwakarta dan sumber berita yang berkaitan dengan penelitian. Uji keabsahan data dilakukan melalui triangulasi data, triangulasi sendiri menurut Sugiyono (2017:274) adalah membandingkan setiap data yang telah diperoleh. Adapun teknik analisis data yang digunakan adalah model interaktif dari Miles dan Huberman dalam Sugiyono (2017:247252) yang terdiri dari tiga tahap, diantaranya: 1) Reduksi data; 2) Penyajian data; dan 3) Penarikan kesimpulan.

\section{HASIL DAN PEMBAHASAN}

\section{Faktor Lingkungan}

Taman Air Mancur Sri Baduga merupakan destinasi buatan yang memanfaatkan sumber daya air di wilayah danau Situ Buleud. Dilansir dari situs Pikiran Rakyat (2019) persepsi masyarakat cenderung tidak akan membayar hanya untuk melihat pertunjukan air mancur karena dirasa tidak bermanfaat. Namun pemerintah Kabupaten Purwakarta sebagaimana dikutip dari situs Ayopurwakarta (2020) masih berupaya melakukan perencanaan terhadap pembiayaan pemeliharaan melalui penerapan retribusi kepada pengunjung Taman Air Mancur Sri Baduga dimana perencanaan retribusi tersebut masih menunggu pengesahan evaluasi hasil evaluasi rancangan peraturan daerah (RAPERDA) oleh DPRD Kabupaten Purwakarta.

Adapun pada aspek lingkungan objek wisata air mancur ini tidak selaras dengan aspek lingkungan. Hal ini dapat dilihat bahwasanya sebagaimana dikutip dari halaman situs Pikiran Rakyat (2019) objek wisata Taman Air Mancur Sri Baduga tidak akan berjalan dengan efektif apabila dijalankan pada musim kemarau, karena pada musim kemarau debit air akan berkurang dan objek wisata tidak akan melakukan kegiatan pertunjukannya.

Sedangkan pada aspek budaya, objek wisata Taman Air Mancur Sri Baduga masih mengusung konsep wisata dengan tema budaya Sunda. Sebagaimana dilansir dari situs Merdeka (2016) yang dimana pada bagian tengah kolam Taman Air Mancur Sri Baduga 
dapat dilihat dari adanya patung Prabu Siliwangi yang merupakan ikon dari objek wisata ini.

Dalam aspek faktor lingkungan dalam pembangunan destinasi pariwisata Taman Air Mancur Sri Baduga Kabupaten Purwakarta masih belum dapat dipenuhi dengan seksama. Secara aspek kebudayaan Taman Air Mancur Sri Baduga sudah dapat berjalan dengan tetap mengusung adat budaya masyarakat Sunda, hanya saja pada aspek masyarakat masih belum diterapkannya sistem pembayaran berbasis tiket untuk dapat menunjang biaya operasional aktivitas pertunjukan air mancur di Taman Air Mancur Sri Baduga, sedangkan pada aspek lingkungan menunjukan bahwa pertunjukan air mancur sangat bergantung pada kondisi musim yang dihadapi oleh wilayah Kabupaten Purwakarta.

\section{Faktor Sumber Daya Manusia}

Faktor sumber daya manusia merupakan sebuah faktor dalam perencanaan pariwisata yang meliputi semua elemen dalam masyarakat yang memiliki kewenangan, kemampuan, ataupun masyarakat sekitar objek pariwisata. Sejak adanya objek wisata Taman Air Mancur Sri Baduga masyarakat yang berada disekitar objek wisata tersebut berkembang secara taraf ekonomi. Hal ini sebagaimana hasil penelitian dari Sioraida dan Anwar (2018) dimana adanya objek wisata air mancur Sri Baduga ini meningkatkan perekonomian masyarakat yang ditandai dengan berkembangnya sektor wirausaha disekitar objek wisata dan masyarakat yang menjadi pemandu wisata ataupun pengelola akomodasi perjalanan pariwisata.

Adapun aspek pengelolaan pada dari segi keterlibatan pemerintah dalam mengelola taman wisata ini masih belum dapat maksimal. Sebagaimana dilansir dari situs Pikiran Rakyat (2019) yang menjelaskan bahwa terdapat fasilitas penunjang seperti kursi yang telah rusak, dan keran air mancur yang keropos. Hal tersebut mengakibatkan wisatawan yang berkunjung tidak puas terhadap pelayanan yang diberikan.
Masyarakat sekitar Taman Air Mancur Sri Baduga yang membuka usaha mendapatkan peningkatan penghasilan dari adanya pertunjukan air mancur di Taman Air Mancur Sri Baduga. Sedangkan pada aspek pengelolaan dari pihak pemerintah yakni DISPORAPARBUD Kabupaten Purwakarta belum dapat dilakukan pemeliharaan secara intens, hal ini dapat dilihat dari fasilitas penunjang seperti kursi hingga keran air yang kondisinya rusak.

\section{Faktor Sistem Yang Digunakan}

Sistem penawaran yang digunakan untuk dapat menarik wisatawan berkunjung untuk memasuki area Taman Wisata Air Mancur Sri Baduga adalah pertunjukan air mancur pada area Situ Buleud secara rutin pada setiap sabtu malam. Dimana selain menonton pertunjukan air mancur sebagaimana dikutip dari situs Tribun Jabar (2019) wisatawan juga dapat berkunjung pada outlet wisata kuliner yang disediakan oleh UMKM di Kabupaten Purwakarta.

Secara penerimaan wisatawan terhadap penawaran yang disajikan dalam area Taman Wisata Air Mancur Sri Baduga antusias berkunjung untuk dapat menyaksikan pertunjukan. Hal tersebut dapat dilihat berdasarkan faktor yang dominan terhadap ekuitas merek dari Taman Air Mancur Sri Baduga menurut Darmawan dan Yusuf (2018) adalah hiburan yang terdapat pada Taman Air Mancur Sri Baduga.

Permintaan dan penawaran terhadap sistem pariwisata tersebut sudah dapat sesuai dengan permintaan wisatawan, dimana hal tersebut selaras dengan faktor penggunaan sistem yang harus sesuai dengan permintaan dan penawaran pada perencanaan pembangunan pariwisata.

\section{Faktor Perkembangan Ilmu dan Teknologi}

Untuk mempromosikan Taman Air Mancur Sri Baduga kepada wisatawan, DISPORAPARBUD Kabupaten Purwakarta menggunakan sarana media sosial untuk memasarkan melalui serangkaian promosi wisata. Hasil dari promosi tersebut dapat 
menarik wisatawan untuk mengunjungi objek wisata Taman Air Mancur Sri Baduga. Hal ini dapat dilihat dari hasil penelitian dari Maulana dan Ri'aeni (2020) yang menjelaskan bahwa secara promosi wisata Taman Air Mancur Sri Baduga dilakukan dengan promosi pada platform media sosial dengan menggunakan dua Bahasa yakni Bahasa Indonesia, dan Bahasa Sunda, dimana pada aspek promosi tersebut sudah dilakukan secara optimal dan efektif untuk menarik perhatian masyarakat.

Selain itu berdasarkan hasil penelitian dari Tiana dan Yusuf (2018) terdapat pengaruh antara Place Branding dan Citra terhadap keputusan mengunjungi objek wisata Taman Air Mancur Sri Baduga. Dimana dalam penelitian tersebut menjelaskan bahwa Place Branding dalam memperkenalkan Taman Air Mancur Sri Baduga kepada wisatawan dapat diterima dengan baik. Selain wisatawan menilai citra Taman Wisata Air Mancur Sri Baduga dinilai baik oleh pengunjung Taman Wisata Air Mancur Sri Baduga.

Dalam hal mengikuti perkembangan ilmu dan teknologi khususnya dalam bidang pemasaran dan promosi Taman Air Mancur Sri Baduga DISPORAPARBUD selaku instansi pemerintah yang mengelola Taman Air Mancur Sri Baduga telah mengikuti perkembangan keilmuan. Dimana promosi wisata tersebut dilakukan melalui media sosial dan mendapatkan respon positif dari pengunjung Taman Air Mancur Sri Baduga.

\section{Faktor Pendanaan}

Pendanaan yang dibuat untuk memelihara dan mengelola Taman Air Mancur Sri Baduga

\section{KESIMPULAN}

Berdasarkan uraian sebelumnya dapat disimpulkan bahwa dalam pengelolaan Taman Air Mancur Sri Baduga bila ditinjau dari teori faktor keberhasilan pembangunan wisata terdapat beberapa faktor pendukung dan penghambat dalam pengelolaannya. Faktor pendukung dari pengelolaan Taman Air Mancur Sri Baduga diantaranya: 1) Faktor adalah menggunakan dana dari APBD Kabupaten Purwakarta. Sebagaimana dikutip dari situs Republika (2020) pemeliharaan Taman Air Mancur Sri Baduga menggunakan dana dari APBD, dana tersebut digunakan untuk biaya perawatan kursi sebesar Rp. 400.000.000,00 dan perawatan air mancur sebesar Rp. 800.000.000,00. Untuk tahun 2020 alokasi anggaran untuk Taman Wisata Air Mancur Sri Baduga sebesar Rp 3,5 Milyar

Menurut keterangan Kepala Bidang Pertamanan dan Penerangan Jalan Umum (PJU) Dinas Tata Ruang dan Pemukiman (Distarkim) Kabupaten Purwakarta dalam situs Republika (2020) jumlah dana tersebut membebani APBD Kabupaten Purwakarta, hal ini memungkinkan bahwa Taman Air Mancur Sri Baduga Kabupaten Purwakarta akan dialihkan pengelolaannya kepada pihak ke-tiga. Selain itu untuk meningkatkan Pendapatan Asli Daerah (PAD) sebagaimana dikutip dari situs Ayopurwakarta (2020) Pemerintah Kabupaten Purwakarta berencana akan menerapkan Retribusi untuk setiap pengunjung yang hendak datang ke Taman Air Mancur Sri Baduga, proses tersebut masih menunggu pengesahan evaluasi hasil evaluasi rancangan peraturan daerah (RAPERDA) oleh DPRD Kabupaten Purwakarta.

Dengan demikian Taman Air Mancur Sri Baduga sudah menjadi prioritas anggaran pembangunan pariwisata di Kabupaten Purwakarta. Hal tersebut dilihat dari perencanaan penggunaan retribusi kepada pengunjung, dan pemeliharaan fasilitas objek wisata Taman Air Mancur Sri Baduga.

hiburan air mancur yang interaktif sehingga menjadi daya tarik wisatawan; 2) Faktor kebudayaan Sunda yang tetap dijaga dan dimanfaatkan untuk menjadi ciri khas objek wisata; dan 3) Faktor pemasaran melalui promosi melalui media sosial. Sedangkan untuk faktor-faktor penghambat tersebut diantaranya: 1) Faktor kondisi fasilitas pendukung yang kondisinya kurang terpelihara; 2) Faktor sumber daya air yang 
menghambat pertunjukan air mancur; dan 3) Faktor pendanaan pengelolaan.

\section{SARAN}

Saran yang diberikan oleh peneliti terhadap permasalahan yang dihadapi pada objek wisata Taman Air Mancur Sri Baduga Kabupaten Purwakarta adalah agar dapat mencari alternatif konsep pendanaan yang dapat berjalan secara berkelanjutan, selain itu Taman Air Mancur Sri Baduga memerlukan konsep manajemen pengairan yang sesuai tema objek wisata. Selain itu disarankan kepada Pemerintah Kabupaten Purwakarta dalam hal ini DISPORAPARBUD untuk dapat mensosialisasikan pentingnya penerapan pembayaran berbasis tiket dan atau retribusi kepada wisatawan agar pemeliharaan objek wisata Taman Air Mancur Sri Baduga dapat berjalan secara keseluruhan.

\section{DAFTAR PUSTAKA}

Sugiyono. 2017. Metode Penelitian Kuantitatif Dan Kualitatif Dan R\&D. Bandung: Alfabeta

Avinda, C. B., Sudiarta, I. N., \& Karini, N. M. O. 2016. Strategi Promosi Banyuwangi Sebagai Destinasi Wisata (Studi Kasus Pada Dinas Kebudayaan Dan Pariwisata). Jurnal IPTA, 4(1), 55-60.

Tiana, D., \& Yusuf, A. 2018 Pengaruh Place Branding Dan Citra Terhadap Keputusan Mengunjungi Destinasi Wisata Taman Sri Baduga Kabupaten Purwakarta. Value: Journal of Management and Business, 3(1).

Herawati, N., \& Winarno, S. B. (2020). Analisis Daya Tarik Wisata Pendukung Kawasan Gunung Api Purba Nglanggeran, Yogyakarta. Journal of Tourism and Economic, 3(1), 58-65.

Hilbig, J., \& Rudolph, K. U. 2019. Sustainable Water Financing And Lean Cost Approaches As Essentials For Integrated Water Resources Management And Water Governance: Lessons Learnt
From The Southern African context. Water Supply, 19(2), 536-544.

Illah, A. N., Sularso, R. A., \& Irawan, B. 2019. Pengaruh Citra Destinasi dan EWOM di Media Sosial Instagram serta Persepsi Konsumen Terhadap Keputusan Berkunjung ke Objek Wisata B29 di Kabupaten Lumajang. e-Journal Ekonomi Bisnis dan Akuntansi, 6(2), 164-170.

Kawengian, F., Lengkong, F. D., \& POMBENGI, J. D. 2018. Perencanaan Pembangunan Sektor Pariwisata Di Kabupaten Minahasa Tenggara. JURNAL ADMINISTRASI PUBLIK, 4(51).

Maulana, R. N., \& Ri'aeni, I. 2020. Analisis SWOT Strategi Komunikasi Pemasaran Pada Taman Air Sri Baduga, Purwakarta. AGUNA: Jurnal Ilmu Komunikasi, 1(1), 37-54.

Mellu, M. R., Besie, J. L., \& Bunga, T. T. 2018. Analisis Faktor Penunjang Dan Penghambat Pengembangan Objek Wisata (Studi Pada Objek Wisata Alam Bola Palelo, Kecamatan Mollo Tengah, Kabupaten Timor Tengah Selatan). Journal of Management: Small and Medium Enterprises (SMEs), 7(2), 269286.

Sjoraida, D. F., \& Anwar, R. K. 2019. The Impact Of The Development Of The Largest Fountain Of Southeast Asia On The Economic Pattern Of The Community. In IOP Conference Series: Earth and Environmental Science (Vol. 248, No. 1, p. 012067). IOP Publishing.

Susanto, D. R., \& Kiswantoro, A. (2020). Strategi Pengelolaan Wisata Susur Sungai Mahakam Berbasis Ekowisata Di Samarinda. Journal of Tourism and Economic, 3(1), 1-10.

Winasis, A., \& Setyawan, D. 2016. Efektivitas program pengembangan desa wisata melalui kelembagaan dalam peningkatan sumber daya alam (SDA). JISIP: Jurnal Ilmu Sosial Dan Ilmu Politik, 5(2).

Wulandari, A., \& Wahyuni, I. I. 2018. Strategi Komunikasi Wisata Taman Air 
Mancur Sri Baduga Situ Buleud Kabupaten Purwakarta. COMMED: Jurnal Komunikasi dan Media, 2(2), 5571.

\section{Artikel Berita:}

http://www.ayopurwakarta.com/read/2019/1

1/27/3674/tingkatkan-pad-taman-airmancur-sri-baduga-akan-ditarik-retribusi diakses tanggal 1 Oktober 2020 Jam 12.20 WIB.

https://www.merdeka.com/peristiwa/mengen al-sosok-sri-baduga-di-balikkemegahan-air-mancur-purwakarta.html diakses tanggal 1 Oktober 2020 Jam 12.20 WIB.

http://www.purwakartakab.go.id/index.php/

Welcome/detail/129 diakses tanggal 30 September 2020 Jam 10.20 WIB.

https://www.pikiran-

rakyat.com/jawabarat/2019/04/20/fasilit as-umum-tidak-terawat-wisatawantaman-sri-baduga-purwakarta-mengeluh diakses tanggal 30 September 2020 Jam 10.20 WIB.

https://republika.co.id/berita/q3txx6368/pem kab-purwakarta-ingin-alih-kelola-airmancur-sri-baduga diakses tanggal 1 Oktober 2020 Jam 12.20 WIB. 